reported suicide attempt were analysed by using a logistic regression model.

Results The prevalence of suicide attempt was $2.7 \%$ and was significantly higher in women than in men (4.6\% vs. $0.9 \%), 65 \%$ used sharp objects, while $26 \%$ and $5 \%$ drug poisoning and hanging, respectively. Almost 19\% reported requiring medical and/or psychiatric services. $28 \%$ of the states of Mexico report prevalences betwen $3.5-5.2 \%$. Variables statistically significant in the model were: age in years $\left(\mathrm{OR}_{\mathrm{A}}=7.57 ; 95 \% \mathrm{CI}:=4.73-12.10\right)$, quadratic age $\left(\mathrm{OR}_{\mathrm{A}}=0.93 ; 95 \% \mathrm{CI}:=.92\right.$ to .94$)$, schooling in years $(\mathrm{OR}=0.90 ; 95 \% \mathrm{CI}:=0.85$ to 0.95$)$, women $\left(\mathrm{OR}_{\mathrm{A}}=6.3 ; 95 \% \mathrm{CI}:=4.94-8.06\right]$, social security $\left(\mathrm{OR}_{\mathrm{A}}=0.80 ; 95 \% \mathrm{CI}:=0.65\right.$ to 0.98$]$ not currently drinking alcohol $\left(\mathrm{OR}_{\mathrm{A}}=2.25 ; 95 \% \mathrm{CI}:=1.74-2.91\right)$ and currently $\left(\mathrm{OR}_{\mathrm{A}}=2.29 ; 95 \% \mathrm{CI}:=1.74-3.01\right)$, not currently smoking tabacco $\left(\mathrm{OR}_{\mathrm{A}}=2.72 ; 95 \% \mathrm{CI}:=2.11-3.51\right)$ and currently $\left(\mathrm{OR}_{\mathrm{A}}=3.2695 \% \mathrm{CI}:=2.48-4.27\right)$, health damage due to interpersonal violence $\left(\mathrm{OR}_{\mathrm{A}}=4.35 ; 95 \% \mathrm{CI}:=3.27-5.80\right)$, having a mild $\left(\mathrm{OR}_{\mathrm{A}}=1.50 ; 95 \% \mathrm{CI}:=1.12-2.01\right)$ and moderate eating disorder $\left(\mathrm{OR}_{\mathrm{A}}=4.22 ; 95 \% \mathrm{CI}:=3.21-5.54\right)$ and being a second degree relative (grandson, nephew, etc) $\left(\mathrm{OR}_{\mathrm{A}}=1.42 ; 95 \%\right.$ $\mathrm{CI}:=1.50-1.77)$.

Conclusions The variables related to suicide attempt are those related to social factors, psychiatric disorders and violence. Studies in Mexico report that a high percentage of adolescents with suicide attemptes have psychiatric disorder. It is urgent to have a better diagnostic and treatment of these disorders.

\section{IMPACT OF ECONOMIC AUSTERITY AND PROSPERITY EVENTS ON SUICIDE IN GREECE: A 30-YEAR INTERRUPTED TIME-SERIES ANALYSIS}

${ }^{1}$ Charles C Branas, ${ }^{2}$ Anastasia E Kastanaki, ${ }^{2}$ Manolis Michalodimitrakis, ${ }^{3}$ John Tzougas, "Elena F Kranioti, ${ }^{5}$ Pavlos N Theodorakis, ${ }^{1}$ Brendan G Carr, ${ }^{1}$ Douglas J Wiebe. ' University of Pennsylvania, Perelman School of Medicine, Philadelphia, USA; ${ }^{2}$ Faculty of Medicine, University of Crete, Iraklion, Greece; ${ }^{3}$ Hellenic Statistical Authority, Piraeus, Greece; ${ }^{4}$ Edinburgh Unit for Forensic Anthropology, SHCA, University of Edinburgh, UK; ${ }^{5}$ WHO National Counterpart for Mental Health, Athens, Greece

\subsection{6/injuryprev-2016-042156.67}

Background The recent strain on the Greek public has prompted academic discussion of the potential health effects of the austerity measures. In this regard, suicides in Greece have been a lead topic, with numerous commentators concluding that the recent austerity measures have led to increased suicides in Greece. This conclusion has, however, been appropriately met with scepticism and no large-scale, systematic longitudinal analysis has been completed to inform the ongoing debate as to whether austerity measures have led to statistically higher suicide rates in Greece.

Methods National data from the Hellenic Statistical Authority were assembled as 360 monthly counts of: all suicides ( $\mathrm{n}=11505)$, male suicides $(\mathrm{n}=9079)$, female suicides $(\mathrm{n}=2426)$ and all suicides plus potentially misclassified suicides occurring in Greece from 1983 to 2012. Twelve austerity-related and prosperity-related events that occurred in Greece during the study period were identified and interrupted time-series analyses using ARIMA models and transfer functions were used to test the impact of each event on suicide.

Results In 30 years, the highest months of suicide in Greece occurred in 2012. New austerity measures in June 2011 marked the beginning of significant, abrupt and sustained increases in total suicides $(+35.7 \%, \mathrm{p}<0.001)$ and male suicides $(+18.5 \%$, $\mathrm{p}<0.01)$. Sensitivity analyses that figured in undercounting of suicides also found a significant, abrupt and sustained increase in June $2011(+20.5 \%, p<0.001)$. Suicides by men in Greece also underwent a significant, abrupt and sustained increase in October 2008 when the Greek recession began $(+13.1 \%$, p < 0.01), and an abrupt but temporary increase in April 2012 following a public suicide committed in response to austerity conditions $(+29.7 \%, \mathrm{p}<0.05)$. Suicides by women in Greece also underwent an abrupt and sustained increase in May 2011 following austerity-related events $(+35.8 \%, \mathrm{p}<0.05)$. One prosperityrelated event, the January 2002 launch of the Euro in Greece, marked an abrupt but temporary decrease in male suicides $(-27.1 \%, \mathrm{p}<0.05)$.

Conclusions This is the first multidecade, national analysis of suicide in Greece using monthly data. Select austerity-related events in Greece corresponded to statistically significant increases for suicides overall, as well as for suicides among men and women. The consideration of future austerity measures should give greater weight to the unintended mental health consequences that may follow and the public messaging of these policies and related events.

\section{School Safety}

\section{Parallel Mon 1.2}

\section{IMPLEMENTATION OF THE 'SCHOOL TRAVEL \& CHILD SAFETY SURVEY' FOR DATA LINKAGE RESEARCH}

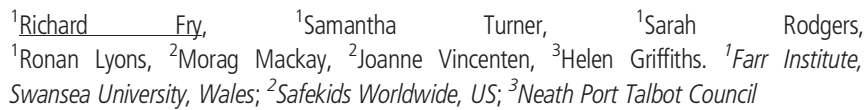

\subsection{6/injuryprev-2016-042156.68}

Background The School Travel and Child Safety Survey (STCSS) was developed as part of the European TACTICS project (Tools to Address Childhood Trauma, Injury and Children's Safety) to address the lack of standardised data on children's safety and exposure to risk across Europe.

Description of the Problem Current methods used to collect data on child safety and exposures to risk are not collected in a coordinated way, making research and policy evaluation in these areas difficult. The STCSS was developed with European partners, as a standardised tool which could be adopted by member states, to collect child safety data and enable comparisons between different regions/countries for policy development and evaluation. Travel behaviour data (e.g. mode of transport and distance travelled) is also limited; but vitally important for monitoring active travel and road safety interventions.

Results The STCSS was developed for children aged 10-13 years to be undertaken in school, and was successfully piloted in 5 countries across Europe $(n=636$, participation rate $=88.37 \%$ ). A sample of children were retested to establish the survey reliability, and per cent agreements were $\geq 96 \%$. The STCSS has been further developed in Wales, to enable the results to be anonymised and incorporated into the Secure Anonymised Information Linkage (SAIL) databank at Swansea University. Data linkage methods within SAIL allow the STCSS results to be linked to other individual and household level datasets; for example, socioeconomic, demographic, health and education data.

Conclusions The ability to link the results from this survey to other routinely collected data in the SAIL database, will provide much needed evidence on the medium and long-term 
effectiveness of child safety interventions and policies; as well as provide regional, national and international policy makers with data to support the planning and evaluation of interventions.

\section{TRAFFIC SAFETY EDUCATION: ITS SUPPORT IN THE CURRICULUM, CULTURE AND WORK OF SCHOOLS IN FINLAND}

Satu Tuomikoski, Laura Loikkanen. Liikenneturva - Finnish Road Safety Council, Finland

\subsection{6/injuryprev-2016-042156.69}

Background Traffic accidents are the number one cause of bodily injuries to children and adolescents. The number of traffic accidents increases as children begin to walk and cycle independently. Expectations for traffic safety education given at school are great but according to many reports, the level and extent of traffic safety education varies greatly from school to school.

Objective In the curriculum reform there was a strong need to secure the quality and extent of traffic safety education while training teachers in practical traffic safety education. Expertise in traffic safety education was offered to those preparing the core curriculum with concrete suggestions about content. Teacher training and updating education were used to increase teachers' knowledge of traffic safety education and to motivate them with practical exercises. The aim was to make traffic safety education in schools more systematic and consistent throughout basic education so that each grade would be given at least 4 hours of traffic safety education integrated into various subjects.

Results Traffic safety education is specified in the content for all grades in the new basic education core curriculum. It is a solid foundation for county and school specific curricula. In the feedback of the 2010-2014 teachers' updating education projects the evaluation of the content and usefulness were excellent and all participants recommended the training to their colleagues. A feedback survey was carried out a year later: most of the respondents still considered the training beneficial. The teachers who attended the day long training belong to a network that is kept informed about current traffic safety related issues.

Conclusions Traffic safety is highly valued but the need to focus on traffic safety education in schools is not always seen. Constant support for schools is paramount and it includes training and motivating teachers, developing new exercises and materials and lobbying at policy level.

\section{SCHOOL INJURIES IN ISRAEL}

${ }^{1}$ Michal Molcho, ${ }^{2}$ Roman Slonakin, ${ }^{2}$ Eli Yafe. ${ }^{1}$ School of Health Sciences, NUI Galway, Galway, Ireland; ${ }^{2}$ Magen David Adom, Tel Aviv, Israel

\subsection{6/injuryprev-2016-042156.70}

Background In the past, first aid for school children was provided by the school nurse, but over the years, this service has been eroded and does not exist anymore in Israeli schools. In 2014, the Ministry of Education, together with the ambulance services in Israel, Magen David Adom, have started a new first aid service that provide service to all schools in Israel. This paper describes the service and the data that were collected as part of it.

Methods A national call centre was established to respond to the first aid needs of all educational institutions in Israel. The service operates 7 days a week, between $07: 30$ to $16: 30$ throughout the school year. In an event of an injury, school staff call the centre, and the call is being taken within 15 seconds. The call centre is occupied at all time by first aids providers. Once a call is received, the service provider assess the situation as describe and decide whether a phone consultation would suffice, whether a first aid providers is required on site, or, in severe cases, whether an ambulance is required. Every call is recorded and entered to a database.

Results Overall, 31217 calls were received to the call centre of which $1 \%$ required ambulance, $16 \%$ were classified as urgent, $72 \%$ were classified as not urgent and $10 \%$ were classified as administrative calls. The majority of those injured were between 10-12 years old. The most common injury place was the playground, followed by sports facility and the classroom. Majority of the injuries occurred during break time. The most common anatomic location of injury was the limbs, followed the head. Most of the injuries occurred during paly, followed by slips and trips and by interpersonal violence.

Conclusions Traditionally, data on injury in the community was based on self-reporting, with very little data that is based on reporting of the care providers. This is one of the few, and most comprehensive study on injuries in schools as reported by first aid providers. As such, this study provides a unique insight on injuries of school children in Israel.

\section{INJURY PREVENTION CAMPAIGNS FOR CHILDREN, BY CHILDREN - THE SAFEKIDS NEW ZEALAND CREATIVE QUEST COMPETITION}

Ann Weaver, Alessandra Francoia. Safekids New Zealand

10.1136/injuryprev-2016-042156.71

Background Scooter-related injuries have doubled every year since 2008-from just 697 claims in 2008 to 6,474 in 2012. Cycling related injuries are one of the top 10 causes of unintentional injury related deaths for children.

Wearing a correctly fitted helmet is proven to reduce the number of head injuries. For cyclists $74 \%$ reduction in the likelihood of severe brain injury. Helmet wearing also reduced the probability of head injury by $69 \%$ in cyclists involved in crashes involving cars.

Despite this, there are significant barriers to helmet wearing among older children. Reasons for this include personal image and peer acceptance; children said they looked 'uncool' and would be teased.

Safekids designed a program that included: Effective engagement with children, schools, families, communities and the media incorporating increased awareness and behaviour change.

Objective In 2012 the Creative Quest competition asked schools to create radio ads, videos and illustrated stories that promoted the importance of wearing helmets.

This presentation will describe the key components and context of this competition, evaluation findings and outcomes. Outcomes to date include broad engagement with 473 entries from 129 teachers at 108 schools.

Results Survey results showed that among those who participated: $83 \%$ learnt how to fit and wear a helmet correctly; $89 \%$ developed a positive attitude towards the use of helmets; $89 \%$ were more likely to wear a helmet; $86 \%$ increased knowledge about the safety benefits of wearing a helmet; and $83 \%$ said they'd do the competition again. 